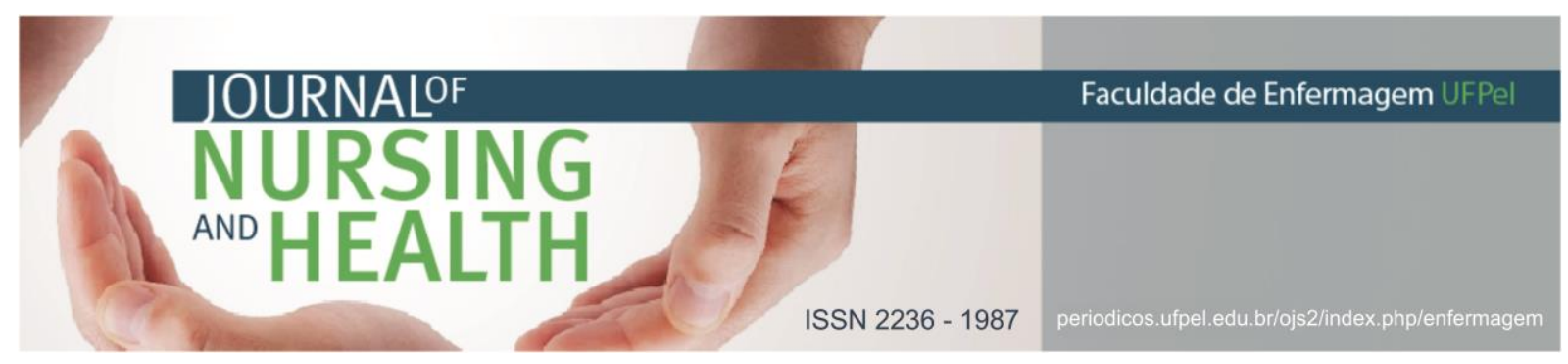

ARTIGO DE REVISÃO

\title{
Para além da alucinação auditiva como sintoma psiquiátrico
}

\author{
Apart from auditory hallucination as a psychiatric symptom \\ Además de la alucinación auditiva como síntoma psiquiátrico \\ Fernandes, Henrique Campagnollo Dávila ${ }^{1}$; Zanello, Valeska²
}

Como citar este artigo: Fernandes HCD, Zanello V. Para além da alucinação auditiva como sintoma psiquiátrico. J. nurs. health. 2018;8(n.esp.):e188414

\section{RESUMO}

Objetivo: problematizar a noção biomédica patológica sobre as alucinações auditivas, através de uma contextualização histórica e cultural. Método: revisão integrativa de literatura, com busca nas bases de dados Publicações Médicas (PubMed) e Portal de Periódicos da Coordenação de Aperfeiçoamento de Pessoal de Nível Superior (CAPES). Os dados foram divididos em cinco subtópicos, referentes aos períodos históricos, a uma nova abordagem do fenômeno no campo da saúde e da cultura. Resultados: na Antiguidade, as alucinações eram um meio de comunicação com as divindades e na Idade Média foram relacionadas à espiritualidade. Culturas que não sofreram influência da medicina ocidental possuem outros vieses sobre o fenômeno. Conclusões: outras formas de compreender as alucinações devem ser consideradas, a fim de evitar a medicalização e o aumento do sofrimento, e proporcionar a criação de possibilidades de existência e convivência do próprio sujeito com sua experiência.

Descritores: Alucinações; Percepção auditiva; História; Cultura.

\section{ABSTRACT}

Objective: to problematize the pathological biomedical notion about auditory hallucinations, through a historical and cultural contextualization. Method: integrative literature review, with search in the Medical Publications (PubMed) and Portal of Periodicals of the Coordination of Improvement of Higher Education Personnel (CAPES). The data were divided into five subtopics, referring to historical periods, to a new approach to the phenomenon in the field of health and culture. Results: in Antiquity, hallucinations were a means of communication with deities and in the Middle Ages they were related to spirituality. Cultures that have not been influenced by Western medicine have other biases about the phenomenon. Conclusions: other ways of understanding hallucinations should be considered in order to avoid medicalization and increase of suffering, and to create the possibility of existence and coexistence of the subject with his or her experience.

Descriptors: Hallucinations; Auditory perception; History; Culture.

\section{RESUMEN}

Objetivo Objetivo: problematizar la noción biomédica patológica sobre las alucinaciones auditivas, a través de una contextualización histórica y cultural. Método: revisión integrativa de literatura, con búsqueda en Publicaciones Médicas (PubMed) y Portal de Periódicos de la Coordinación de

1 Psicólogo. Mestre em Psicologia Clínica e Cultura. Faculdades Integradas da União Educacional do Planalto Central (FACIPLAC). E-mail: hcdfernandes@gmail.com http://orcid.org/0000-0001-9976-8551

2 Psicóloga. Bacharel em Filosofia. Doutora em Psicologia. Universidade de Brasília (UnB). E-mail: valeskazanello@gmail.com http://orcid.org/0000-0002-2531-5581 


\section{JOURNALOF

Perfeccionamiento de Personal de Nivel Superior (CAPES). Los datos fueron divididos en cinco subtemas, referentes a los períodos históricos, a un nuevo abordaje del fenómeno en el campo de la salud y la cultura. Resultados: en la Antigüedad, las alucinaciones eran un medio de comunicación con las divinidades y en la Edad Media se relacionaron con la espiritualidad. Culturas que no han sufrido influencia de la medicina occidental poseen otros sesgos sobre el fenómeno. Conclusiones: otras formas de comprender las alucinaciones deben ser consideradas, a fin de evitar la medicalización y el aumento del sufrimiento, y proporcionar la creación de posibilidades de existencia y convivencia del propio sujeto con su experiencia.

Descriptores: Alucinaciones; Percepción auditiva; Historia; Cultura.

\section{INTRODUÇÃO}

A experiência de ouvir vozes (que ninguém mais ouve) é entendida pelas sociedades modernas ocidentais como sintoma de doença mental. ${ }^{1}$ Nomeada pela medicina como alucinação auditiva, ela constitui o espectro da esquizofrenia. ${ }^{2-3} \mathrm{E}$ é associada também a outros quadros psicopatológicos como os transtornos de humor, borderline e de abuso de substâncias e a transtornos neurológicos - como epilepsia e mal de Parkinson. ${ }^{4}$

Popularmente, tal fenômeno possui diversos sentidos, entre eles, o de dom espiritual, sinal de loucura ou possessão demoníaca. Ele pode se manifestar como imagens mentais auditivas, pensamentos vívidos e intrusivos, e percepções de ouvir vozes e sons. ${ }^{5}$ Pode haver, também, a sensação de que as vozes sejam geradas por outra entidade. ${ }^{6} \mathrm{Em}$ todo caso, é o aspecto da alteridade, nas vivências, que as torna tão convincentes - é uma experiência de "estar sendo comunicado". 7

A alucinação auditiva é definida como percepção que ocorre sem estímulo externo, distinta do pensamento. ${ }^{3} 0$ termo "alucinação" foi popularizado por Esquirol em $1838^{8}$, e tem uma etimologia polêmica. Significa "a ação e efeito de alucinar". 9:261 Cícero foi o primeiro a utilizá-lo, com a palavra halucinatus. ${ }^{10}$ Alucinação vem do latim ālūcinnātĭo: "vaguear da mente, devaneio". 10:99

0 termo alucinar vem do grego $\dot{\alpha} \lambda u ́ \omega$, e foi traduzido para o latim como ālūcĭnor, do infinitivo alūcinārī. 10 Significa "aberro"10:99 desvio da normalidade -, "delírio"10:99, "insanidade"10:99, "não seguir nenhuma linha de raciocínio"10:99, "divagar livremente"10:99, e "ter o espírito extraviado".9:261 A palavra alucināri pode ser decomposta em "ad" e "lucināri", que significa "a ponto de iluminar/brilhar". 9:261

Esse fenômeno tem sido tratado dentro do modelo da causalidade genética, dominante na psiquiatria ${ }^{11}$, por meio de medicações que visam sua remissão. Elas possibilitam que muitas pessoas vivam sem necessitarem de internação, mas muitos usuários do sistema público de saúde mental de nosso país, que usam antipsicóticos, relatam que continuam ouvindo vozes. Dependendo da dosagem e do tempo de uso, as medicações provocam problemas como ganho de peso, hiperlipidemia, disfunção cardíaca e sexual, catarata e diabetes mellitus doença que, no Texas (EUA), afetou, em um ano, 6.9\% dos 332 pacientes acompanhados. ${ }^{12}$ 


\section{JOURNALOF \\ NURSING \\ AND HEALTH}

Tais fatores podem agravar o sofrimento e modificar as experiências sintomáticas, 0 que leva alguns pesquisadores a crerem que o modelo biológico da psiquiatria é insuficiente nos parâmetros de recuperação. ${ }^{11}$ É necessário, então, problematizar a forma como o tratamento medicamentoso vem sendo conduzido e entender que elementos como o contexto de vida e o ambiente social e familiar devem ser explorados, já que eles têm uma importante relação com a saúde mental das pessoas que escutam vozes. ${ }^{6}$

Neste estudo utilizaremos também a expressão "audição de vozes", a qual tem sido empregada pela literatura especializada. ${ }^{13}$ Embora associadas a diagnósticos psicopatológicos, as vozes são ouvidas por pessoas que não precisam de cuidados profissionais ${ }^{5}$ : os ouvidores de vozes "não-clínicos"4 ou "nãopacientes" 4 , que representam de 0,8\% a $31,4 \%$ da população de alguns países. ${ }^{14}$

Ao longo da história do Ocidente, a audição de vozes nem sempre foi compreendida como sintoma de doença, tendo recebido diferentes sentidos. Este artigo objetivou problematizar a noção biomédica através de uma contextualização histórica e cultural, conforme os procedimentos descritos a seguir.

\section{MATERIAIS E MÉTODOS}

O presente estudo se trata de uma revisão integrativa de literatura, que se deu no período de agosto de 2015 a dezembro de 2016. Para tal, adotou-se as seguintes etapas ${ }^{15}$ : definição da pergunta de pesquisa,
ISSN 2236 - 1987

busca na literatura, coleta dos dados, análise dos estudos incluídos, discussão dos resultados e apresentação da revisão integrativa. Assim, a questão que norteou a pesquisa foi: Que formas de compreensão sobre as alucinações auditivas, ao longo da história e de culturas no Ocidente, são diferentes da postulada pela lógica da medicina moderna?

Foi realizada uma busca livre e interessada na internet, de produções nacionais e internacionais, por meio de duas bases de dados: o Portal de Periódicos da CAPES e Publicações Médicas (PubMed), com os descritores "audição de vozes", "história" e "cultura", nos idiomas português e inglês, utilizando-se 0 booleano "AND". Por se tratar de uma contextualização histórica e cultural, não houve delimitação de período de publicação dos artigos, tendo sido adotado como critério de inclusão a disponibilidade online e a gratuidade. Excluíram-se deste trabalho os estudos que trouxeram formas de compreensão alinhadas com a lógica biomédica. Alguns livros e capítulos de obras também foram estudados e referenciados.

Posteriormente foi feita uma leitura de todo o material selecionado, e a análise e interpretação dos dados, os quais foram organizados dentro de cinco subtópicos: três divididos entre os períodos históricos - Antiguidade, Idade Média e Modernidade; um que trata da abordagem que criou uma linhagem alternativa à perspectiva biomédica, dentro do campo da saúde; e uma última sobre cultura, de acordo com os conteúdos disponibilizados a partir do próximo tópico. 


\section{NURSING AND HEALTH}

ISSN 2236 - 1987

\section{RESULTADOS E DISCUSSÃO}

\section{Mensagens de guias do espírito: audição de vozes na antiguidade}

Até 1300 a.C. era comum as pessoas ouvirem vozes, as quais as orientavam na tomada de decisões ${ }^{16}$ como na "Ilíada" de Homero, obra repleta de diálogos entre homens envolvidos na Guerra de Tróia e deuses que elaboravam suas estratégias e os encorajavam nas batalhas. Na Grécia antiga, a audição de vozes era uma questão central para o funcionamento dos oráculos, que atraiu Estados e pessoas em busca de orientações divinas. ${ }^{17}$ Elas também foram registradas entre os egípcios, romanos e babilônios, cujos sacerdotes utilizavam-nas como mensageiras e guias espirituais. ${ }^{18}$

No cenário grego, Sócrates foi um dos primeiros filósofos a relatar que escutava vozes. Ele afirmou que ouvia um daimon: a voz da sabedoria, um guia pessoal útil, diferente dos pensamentos - pois tinha uma qualidade sensória verbal. ${ }^{19}$ Essa voz tinha uma atuação benéfica no intuito de viabilizar algumas situações e impedir a ocorrência de outras. ${ }^{17}$ Ainda assim, Sócrates sabia que poderia ter problemas com esse tipo de experiência e que ela poderia ser confundida com loucura. ${ }^{18}$

Outro grego a ser destacado é Aristóteles. Ao teorizar sobre sonhos, ele afirmou que "a faculdade que produz nossa ilusão quando doentes durante a vigília é a mesma que produz esse estado passivo durante o sono". 20 A palavra "doença", nesse texto, faz referência à cólera, melancolia ou febre (que pode se manifestar como um estado delirante). O termo ilusão se refere a percepções distorcidas de objetos, captadas pelos sentidos, que podem ser influenciadas pelas emoções das pessoas. Assim, segundo o filósofo, experiências de visões e audição de vozes poderiam acontecer com qualquer ser humano.

No cenário romano, dois reinados foram marcados por "alucinações sistemáticas"21: o de Tibério e o de Nero. No primeiro, houve uma enorme proliferação do messianismo, inspirada na teoria que previa a vinda do Cristo Salvador e que foi repleta de mitos e comportamentos exaltados. No de Nero, e por vários anos, a expectativa da vinda de um anticristo e a adoração religiosa fizeram surgir o fanatismo judaico, que dominou as classes e suspendeu a vida pública, criando em todo o país um clima de loucura. As pessoas viviam em estados alucinatórios constantes e espalhavam rumores de visões de espadas e cometas nos céus, batalhas nas nuvens e luzes brilhando à noite. ${ }^{21}$

Nas tradições cristã e hebraica, a palavra, entendida como som, estabeleceu uma presença pessoal da divindade, e assim articulou um sentido religioso imediato: 0 envolvimento da pessoa com a situação presente de Deus. ${ }^{22}$ Foram escritas ${ }^{23}$ diversas passagens sobre a comunicação humana com Deus, em variadas formas: vozes, sinais, visões e mensagens de anjos. Santo Agostinho procurou explicar essa forma de comunicação ao tecer considerações sobre as visões místicas de Paulo, a partir do mandamento "Amarás ao teu próximo como a ti mesmo". ${ }^{24}$ 


\section{JOURNALOF \\ NURSING \\ AND HEALTH}

Para tal, ele as dividiu em três níveis: o corpóreo, quando vemos a palavra (nível físico); o espiritual, quando a imagem do próximo é vista sem ele estar lá (nível imaginativo); e o intelectual, quando entendemos e "vemos" o conceito de amor. O teólogo enfatizou que a divindade não era algo corpóreo e que a aproximação a ela se daria por meio dos outros dois aspectos. Em razão disso, os místicos avaliavam a pertinência das experiências (visão e audição de vozes) conforme seu nível. ${ }^{24}$

$\mathrm{Na}$ Antiguidade, portanto, as alucinações não significavam sinal de doença ou loucura - a qual para os gregos significava hybris, ou perda da medida ${ }^{25}$ - e, no período histórico que se sucedeu, elas ganharam outros sentidos.

\section{Possessão demoníaca ou santidade? audição de vozes na idade média}

A Idade Média foi um período marcado pela expansão do cristianismo, que estruturou a vida de grande parte das sociedades europeias. ${ }^{26}$ A doutrina cristã recebeu a influência de líderes religiosos que ouviam vozes - como Martinho Lutero, Teresa de Ávila, Francisco de Assis, Joana d'Arc, Santo Agostinho e São Tomás de Aquino - e de suas experiências alucinatórias. ${ }^{17}$

$A$ audição de vozes ganhou maior visibilidade no século $\mathrm{XI}$, quando toda a Europa foi assolada por um grande terror ocasionado pela crença no fim do mundo. As Cruzadas se iniciaram e, no século XII, provocaram grande entusiasmo entre os adultos $e$ as crianças, com o "missionismo
ISSN 2236 - 1987

heróico"21 - o qual os levou a se lançarem em territórios incitados por vozes e visões sobrenaturais (entre elas a de Deus), pregando guerra aos infiéis. Nos séculos seguintes, epidemias de pessoas sofrendo com alucinações continuaram acontecendo na Europa.

No século XIII foi instituída a diferença entre percepções falsas e normais, e as vozes foram compreendidas como fenômenos naturais provocados pelo demônio ou por Deus. ${ }^{27}$ A Igreja Católica foi influenciada a interpretar alguns desses fenômenos como feitiçaria/bruxaria. ${ }^{28}$ Isso porque, diferentemente dos místicos, os escolásticos avaliavam a pertinência da visão segundo seu conteúdo e fonte, ou seja, se ela tinha a ver com o imaginário de reinos celestiais ou infernais. ${ }^{24}$

Ao final do século XIV a audição de vozes foi mais frequente na França. ${ }^{21}$ Em Lausanne e Berna, pessoas que tinham visões e ouviam vozes afirmaram, diante dos tribunais, que pactuaram com o demônio e se alimentaram de carne humana. Em Artois, mais de 90 mulheres foram condenadas e queimadas por conta das alucinações. O tribunal da Inquisição foi responsável não só por levar à morte pessoas que confessavam crimes que não haviam cometido (influenciadas pelas vozes e visões), como contribuiu para produzir mais alucinações e alucinados.

Dessa forma, com a escolástica corrente dominante nas universidades medievais $^{29}$-, a Igreja Católica reivindicou 0 direito de julgar ouvidores de vozes conforme quatro 


\section{NURSING \\ AND \\ HEALTH}

categorias: possessão, bruxaria, heresia e canonização. ${ }^{18}$ Havia, portanto, duas possibilidades para eles: a condenação ou a salvação. Muitos foram considerados anormais ${ }^{28}$, e os que eram dissidentes do cristianismo foram considerados loucos endemoniados, perseguidos e condenados. ${ }^{30}$

Joana d'Arc passou por esse processo. Aos doze anos de idade, ela recebeu uma mensagem dos céus, de que deveria libertar seu povo dos ingleses e salvar seu país. Passou a ouvir vozes e ter visões de santos. Aos dezoito anos, Joana se apresentou ao delfim Carlos VII; convenceu-o de que lutaria contra os ingleses na Guerra dos Cem Anos e o conduziria ao trono da França. Liderou suas tropas e foi vitoriosa em inúmeras batalhas, tendo também as vozes e visões como suporte, inclusive quando foi gravemente ferida. ${ }^{31}$

Ao ser capturada pelos ingleses, Joana foi acusada de bruxaria e de possessão demoníaca, e foi julgada pela Inquisição. No decorrer do processo, ela foi, também, considerada herege, por não ter se submetido a determinações da Igreja como vestir roupa de mulher e ser obediente aos pais. Foi condenada e queimada na fogueira. No século XIX, a Igreja Católica atribuiu causa divina aos seus feitos, retirou a condenação, e responsabilizou o clero inglês, por ter misturado fé com questões políticas. Sua canonização aconteceu em 1920, quase cinco séculos após sua morte. ${ }^{31}$

$E$ ainda como destaque nesse período, temos a obra de Teresa de Ávila "O castelo interior" ${ }^{32}$, na qual foi escrito que Deus se comunicaria
ISSN 2236 - 1987

conosco através de uma voz, que poderia vir de dentro (da alma) ou ser tão exterior como uma voz real. $\mathrm{Na}$ maior parte das vezes, se tratava de uma fantasia, especialmente "com pessoas de uma imaginação muito viva"32 ou melancólicas.

A estratégia de Teresa (que era ouvidora de vozes e vivenciava outros fenômenos "místicos") teve como intuito proteger as freiras que sofriam com experiências sobrenaturais da Inquisição. ${ }^{24}$ Ela contribuiu para retirar o protagonismo do tribunal inquisitório nos julgamentos, ao lado de outras autoridades que reivindicavam o seu desmantelamento. No entanto, outro personagem é nomeado para julgar esses casos: o médico.

Assim, Teresa contribuiu para trazer a ciência para o centro das explicações sobre as experiências sobrenaturais e deixar a Igreja em segundo plano. Ou seja, ela abriu possibilidade para que a audição vozes - até então avaliada como uma questão política, entre os gregos, e teológica, entre os medievais - ganhasse um novo caráter: o de sintoma de doença, como veremos a seguir.

\section{Sintoma de doença mental: audição de vozes na modernidade}

A Modernidade teve início com uma crise no pensamento medieval europeu, gerada a partir de três acontecimentos históricos de grande vulto: a Reforma Protestante, o Movimento Iluminista e a Revolução Francesa. ${ }^{33}$ Os métodos de averiguação da realidade se modificaram através da ciência emergente, estruturada a partir de teóricos como Bacon, Galilei, 
 \\ A \\ 政}

e Kepler, Newton e Descartes - com o seu racionalismo idealista. ${ }^{34}$

O movimento que teve início com Teresa de Ávila teve duas consequências negativas: a) as "doenças da alma" ("imaginárias") passaram a ser compreendidas e analisadas em analogia direta com as do corpo, o que levou ao b) aumento da demanda por médicos para o tratamento. Formados por uma lógica Greco-Latina, os médicos passaram a descrever as "doenças da alma" de forma objetiva, traçar os diagnósticos e medicar. Com a modificação do sistema de linguagem para a explicação da realidade, termos teológicos utilizados pela Inquisição e pela religião - como satânico, divino, mais baixo, elevado - foram substituídos por conceitos científicos, como doente, enfermo, ineficiente, erro. ${ }^{24}$

No século XVIII as alucinações passaram a ser explicadas de diversas formas: por uma neurofisiologia vibratória, como causa de delírios, como uma comorbidade orgânica, ou como insanidade. ${ }^{35} \mathrm{E}$ surgiu um novo tratamento para os "doentes", a internação asilar, promovida por Battie em Londres, Chiarugi em Florença e Pinel em Paris. Com isso, o número de pacientes em asilos aumentou, e foi possível ao médico traçar um panorama da insanidade. ${ }^{17} \mathrm{~A}$ legitimação desse sistema consolidou as práticas manicomiais no século XIX, quando a psiquiatria surgiu como especialidade. ${ }^{36} 0$ psiquiatra passou, então, a ser o responsável pelos doentes mentais e seu tratamento.

Esquirol (aluno de Pinel) foi o primeiro professor de medicina
ISSN 2236 - 1987

mental, em seu curso de 1817 - ano em que lançou o termo alucinação. ${ }^{8}$ Sobre esse fenômeno: "uma pessoa é dita se enganar com uma alucinação, ou ser um visionário, quando tem uma convicção profunda da percepção de uma sensação, quando nenhum objeto externo, adequado para excitar essa sensação, impressiona os sentidos". ${ }^{37}$

A partir daí a escola francesa passou a ser a referência em pesquisas sobre alucinações na Europa. Nas décadas de 1820 e 1830, três pesquisadores franceses se destacaram em suas teorizações: Alexis Berbiguier, François Leuret, e Louis Lélut, que concordaram quanto ao fato de elas serem da ordem da loucura. ${ }^{35} \mathrm{Na}$ década de 1840 as produções aumentaram, em razão de um concurso promovido pela Academia Real de Medicina de Paris, e, em 1855, a Sociedade Médico-Psicológica de Paris tomou a frente de um ciclo de debates.

Em ambas as ocasiões, foram discutidas questões como o caráter de normalidade, a relação entre imagem, alucinação e sensação, a similaridade entre sonhos, transe e alucinações, ou se as experiências tinham origem psicológica. Apesar das conclusões dos alienistas, o nível das discussões ficou mais no plano teórico, e os eventos se encerraram sem resultados conclusivos. ${ }^{35}$

A partir da segunda metade do século XIX, a psiquiatria francesa não dominava mais o cenário europeu, e teóricos de outros países começaram a se destacar, com uma produção baseada na neurofisiologia. ${ }^{38}$ No entanto, dois trabalhos publicados ao final desse século procuraram sair de tal enfoque. Gurney, em 1886, realizou 


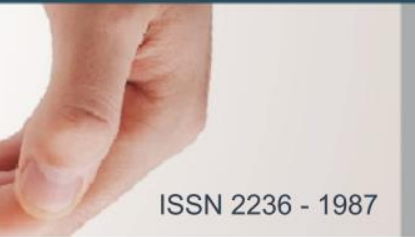

uma pesquisa experimental, relacionando telepatia, alucinações e amostras "normais" da população que alucinavam. Procurou tematizar bruxaria, magia, hipnose e religião, sem desconsiderar o caráter patológico de algumas manifestações. ${ }^{8}$

O outro trabalho foi de Tito Lívio de Castro. ${ }^{8}$ Ele afirmou que os conteúdos das alucinações tinham relação com fatores étnicos, sociais e individuais, e que as imagens imprimiam às alucinações peculiaridades de uma época, de uma profissão ou uma raça, emprestandothes elementos originais. Para reforçar sua tese, Castro apresentou casos clínicos, como o de um padre que via um demônio atiçando-o de forma pecaminosa, com imagens de mulheres nuas. ${ }^{21}$

Outro caso de destaque citado foi o de um homem que relatou estar com sapos no estômago. Muito irritado pelas contestações de algumas pessoas que o ouviam, ele "levou a mão à boca para receber os sapos regurgitados e fez o gesto de arremessá-los ao rosto de seus contraditores" - o que nos remete à noção da alucinação como metáfora. A diferença de gênero também foi problematizada, ao ser afirmado que as alucinações das mulheres histéricas tinham relação não só com a posição social que elas ocupavam, à época, como também com a educação que receberam desde cedo - inclusive a religiosa. ${ }^{21}$

Ao final do século XIX, a escola alemã passou a ser a referência internacional no campo da audição de vozes, principalmente em função dos trabalhos de Kraepelin. A partir da quarta edição de seu manual de psiquiatria, em 1893, Kraepelin afirmou que elas eram sintomas característicos e prelúdios da dementia praecox. ${ }^{39}$ Depois de Kraepelin, cabe destacar na Era Moderna mais dois personagens, os quais foram fundamentais para firmar a tradição que "patologiza" as alucinações: Eugen Bleuler e Kurt Schneider.

Em 1911, Bleuler deixou de lado o termo dementia praecox de Kraepelin, pois "precoce" e "demência" não seriam termos aplicáveis a todos os pacientes. Preferiu a palavra esquizofrenia, por carregar a ideia de "divisão de diferentes funções psíquicas". ${ }^{40}$ Assim como Kraepelin, ele afirmou que seus sintomas mais característicos seriam as alucinações e os delírios. Além disso, Bleuler ampliou as categorias, centrando seus esforços na sintomatologia - questão que foi um marco para a nosologia psiquiátrica.

E Schneider, em 1948, publicou a obra "Psicopatologia clínica" 41 , na qual lançou o conceito de "sintomas esquizofrênicos de primeira ordem"42 os quais representariam a "perda do contorno do eu" em relação ao mundo, e que foram, a partir de então, considerados como essenciais para a diagnose da esquizofrenia. Nas palavras do próprio autor, as alucinações auditivas tinham "um valor diagnóstico extraordinário para a admissão de uma esquizofrenia". ${ }^{42}$

Com isso, Schneider estabeleceu contornos específicos para tal quadro clínico (reduzindo as noções que se tinha até então) e influenciou de forma crucial os manuais diagnósticos que se seguiram posteriormente, como o CID10 e o DSM-3. ${ }^{43}$ Com os sintomas de 


\section{JOURNALF

primeira ordem de Schneider, a Organização Mundial da Saúde (OMS) passou a considerar a esquizofrenia como um "transtorno psiquiátrico universal". ${ }^{41}$ Assim, Schneider contribuiu para reforçar a audição de vozes não só como sintoma de doença, como também para o estigma da loucura.

Outras formas de compreensão das alucinações, no século XX, foram desenvolvidas, e vários psicopatólogos produziram obras que ainda hoje são pesquisadas - mas seria inviável citálas neste trabalho. Porém, em razão da lógica biomédica ser apenas uma possibilidade de compreensão do fenômeno e, por si só, insuficiente para o cuidado, é necessário apresentarmos outras que têm contribuído atualmente para a ampliação da temática.

Deste modo, é importante citar a metodologia desenvolvida pelo Movimento Internacional de Audição de Vozes, em inglês Hearing Voices Movement (HVM), a qual tem colocado em xeque a noção patológica das alucinações, bem como a existência de culturas que lidam de forma diferente com tal fenômeno.

\section{O movimento internacional de audição de vozes}

O psiquiatra holandês Marius Romme atendia uma paciente de 30 anos de idade, Patsy Hage, a qual já havia sido internada diversas vezes, sem que as alucinações auditivas melhorassem, e pretendia se suicidar para pôr fim ao sofrimento insuportável que elas causavam. Após ler uma obra que continha uma abordagem diferente da biomédica ${ }^{16}$,
Patsy passou a entender que as vozes eram uma manifestação normal da vida, e questionou Romme quanto à sua escuta. 0 psiquiatra, então, mudou sua postura, possibilitando a ela superar a ideação suicida, ter mais autonomia em relação ao que as vozes falavam e sair da situação de isolamento. ${ }^{44}$

Eles decidiram ir a um programa de televisão e lá convidaram pessoas que escutavam vozes para contatá-los e contarem sobre suas experiências. Das 700 pessoas que ligaram, 300 achavam que podiam lidar com elas e 150 utilizavam estratégias de enfrentamento. ${ }^{44}$ A partir daí, organizaram o primeiro congresso de ouvidores de vozes, ocasião em que se discutiram questões relativas ao fenômeno.

Foram elencadas três fases para o processo de lidar com as vozes: a surpreendente, que tem início com uma experiência assustadora, com a voz vindo subitamente; a fase de organização, que é um processo de comunicação e seleção com as vozes; e a de estabilização, em que a pessoa consegue adquirir uma lida estável com elas. Concluiu-se, ainda, que a visão patológica sobre o fenômeno é ineficaz e infrutífera para auxiliar na compreensão do que está se passando. ${ }^{44}$

Hage deu o passo inicial para o desenvolvimento do HVM. ${ }^{45}$ Além do congresso, Romme, a pesquisadora Sandra Escher e outros ouvidores de vozes começaram a realizar grupos terapêuticos na Holanda, que, logo depois, ganharam espaço também na Inglaterra. Neste país, foi formada, em 1988, a primeira "Rede de Audição de 
vozes", o $\mathrm{HVN}^{46}$, que se expandiu internacionalmente. As HVNs são coordenadas desde 1997 pela Rede Internacional para Treinamento, Educação e Pesquisa em Audição de Vozes (INTERVOICE). ${ }^{46}$

Todas essas redes formam o coletivo do HVM, cuja prática, filosofia e política estão embasadas em princípios estabelecidos por Romme, Escher e ouvidores de vozes, entre eles: que as vozes são manifestações normais da existência e devem ser interpretadas e compreendidas a partir de relatos de ouvidores de vozes e seus acontecimentos ou contextos de vida; e que o fenômeno tem início pela primeira vez e continua sendo mantido em função de questões que desempoderam e/ou são devastadoras para a pessoa. ${ }^{46}$

O HVM conta com ativistas e profissionais de diversas áreas, grupos de apoio e redes de suporte, tendo como objetivos: problematizar a lógica biomédica tradicional, redefinir questões relativas a competências e poderes, desenvolver estratégias de recuperação e lida com as vozes, e promover o ativismo político em defesa dos direitos de ouvidores de vozes. ${ }^{47}$

A metodologia de suporte do HVM ocorre em duas etapas, considerando que há uma grande relação entre a história de vida, as vozes e a forma pela qual a pessoa lida com elas. ${ }^{48} \mathrm{~A}$ primeira consiste em explorar elementos que fazem parte de aspectos fenomenológicos das vozes: identidade, características, conteúdo, história e gatilhos que as despertam. Terminada essa etapa, a pessoa é estimulada e auxiliada a se tornar protagonista do processo de recuperação, construindo redes de suporte, trabalhando suas emoções e passando para uma posição ativa de enfrentamento. As vozes são personagens importantes desse processo e passam a ganhar sentido no seu desenrolar. ${ }^{49}$

Os grupos de audição de vozes sempre foram um dispositivo central dentro dessa metodologia. Além de explorarem aspectos fenomenológicos, eles se destinam a proporcionar um ambiente de troca de experiências sobre o sofrimento ocasionado pelas vozes. ${ }^{50}$ Com isso, as pessoas são capazes de se sentirem mais seguras e de construírem narrativas plenas de sentido para suas vidas - já que se ajudam na análise das vozes a partir de seus sentidos simbólicos. Além disso, "o grupo pode ajudar a promover a atenção a gatilhos, padrões e explicações que a pessoa pode não perceber ou ser capaz de formular por conta própria". 50

Esse tipo de grupo se diferencia de outros grupos de suporte por não possuir um formato estruturado (como o “Alcoólicos Anônimos"), tampouco exigir um profissional da área da saúde para coordená-lo - apenas um facilitador que tenha como postura basilar a disposição para a escuta e a sensibilidade para mediar crises que porventura aconteçam durante os encontros. Quem coordena e toma decisões sobre o grupo são seus próprios frequentadores, e isso é realizado de forma democrática questão que subverte a lógica hierárquica tradicional dos tratamentos clínicos de profissionais da área da saúde. ${ }^{50}$ 
Através da filosofia e da metodologia do HVM, ouvidores de vozes de vários países têm conseguido estabelecer uma melhor convivência com suas experiências, e realizar a quebra do ciclo de internações e tratamentos tradicionais - questão que proporcionou maior autonomia em suas vidas. ${ }^{47}$

\section{Para além da lógica biomédica: cultura e audição de vozes}

A cultura molda as alucinações em todas as suas dimensões: conteúdo, experiência, frequência, significados, identificação, na forma como as pessoas respondem e na angústia que elas despertam. Ela exerce também influência na formação de audição de vozes patológicas ou não. ${ }^{51}$ Além desses aspectos, o ambiente em que a pessoa está inserida tem maior poder de influenciar o conteúdo das alucinações do que a cultura de origem. ${ }^{52}$ Portanto, no cuidado e suporte a ouvidores de vozes, há que se considerar esses fatores.

Um estudo que comparou experiências de ouvidores de vozes de diferentes sociedades (realizado em cidades da Índia, Gana e dos Estados Unidos) trouxe dados importantes quanto à influência da cultura. ${ }^{53}$ Os resultados indicaram que os estadunidenses tiveram experiências mais intensas e agressivas, com vozes de comando, e se utilizaram de categorias diagnósticas para explicar as vivências. Os indianos escutavam vozes com conteúdos sexuais e brincadeiras, enquanto os ganeses relataram ter tido experiências com a voz de Deus.
Ou seja, diferentemente dos estadunidenses, os outros dois públicos interpretaram as vozes com uma ideia de relação com a alteridade, de forma confortável - apesar de viverem em cidades mais caóticas e barulhentas do que os primeiros. Essa diferença pode ter sido decorrente da ênfase da cultura norte-americana na autonomia individual, que considera a audição de vozes sintoma de doença mental, que invade e assalta o mundo privado, e que os pacientes têm o direito e devem ser informados sobre seus diagnósticos. 53

No Brasil, algumas etnias desestabilizam e desafiam os sentidos dados às alucinações pela psicopatologia tradicional. $\mathrm{Na}$ etnia Kamayurá, no Alto Xingu, o som "ihu" 54 - é originado com o choque de dois elementos e chega aos ouvidos pelo ar, sendo também buscado e captado ativamente por esse órgão - o que indica que a percepção ocorre de forma ativa e passiva, simultaneamente. O conhecimento do sistema auditivo e fonador para eles é muito importante, e o mundo se torna inteligível por meio de sons emitidos no ambiente, os quais são imediatamente detectados e decodificados.

Em virtude da elevada capacidade de identificar e discernir sons da natureza - "humanos e nãohumanos"54 -, os Kamayurá se comunicam com 'animais e espíritos' 54 que encontram nos deslocamentos pela floresta, pela emissão de sinais vocais e sonoros que têm a finalidade tanto de informar que não causarão mal algum a esses seres, quanto de solicitar que eles também assim procedam. ${ }^{54}$ 


\section{JOURNALOF \\ NURSING \\ AND HEALTH}

ISSN 2236 - 1987

Outra etnia que merece destaque é a dos Kaxinawa, que vive nos territórios fronteiriços entre Brasil e Peru. ${ }^{55}$ Quando alguém escuta algo que não pertence à esfera comum de outrem, não se questiona se realmente ele escutou. Alucinar significa perceber alguma coisa através de um ou mais sentidos. $E$, por ser um caso extraordinário de percepção, é avaliado conforme três pontos: o estado em que o perceptor se encontrava, a qualidade do que foi percebido e o contexto em que a percepção ocorreu. ${ }^{55}$ Deste modo, fica evidente, nessa etnia, que há o reconhecimento e o respeito à alteridade, além da valorização das experiências.

Da mesma forma, em uma pesquisa sobre os Yanesha, etnia indígena localizada no Peru central, as ideias dessa etnia sobre sensorialidade e ser humano são mais complexas em comparação àquelas dadas pelas sociedades ocidentais. ${ }^{56}$ No entanto, a noção de sensorialidade é estendida para além dos cinco sentidos do corpo, acrescentando-se dois elementos não corpóreos: "yecamquën ("nossa alma/vitalidade") e yechoyeshem ("nossa sombra")". ${ }^{56}$ Os cinco sentidos do corpo são considerados meios imperfeitos de conhecimento, enquanto é a vitalidade que possibilita à pessoa chegar ao conhecimento da verdade - ou seja, à essência das coisas. É ainda a vitalidade que torna as pessoas capazes de apreenderem dimensões espirituais de objetos e seres não só deste, como também de outros mundos.

A audição, para os Yanesha, é o órgão das vitalidades mais valorizado, e os conhecimentos espirituais mais importantes são recebidos por meio de revelações audíveis de seres - através do uso de plantas alucinógenas ou em sonho. Consideram que o conhecimento extraordinário (dimensão espiritual) é o que deve importar, e que o corpo "é o lócus do conhecimento, não o seu agente causador". 56

Essa noção desloca o pensamento de que a pessoa não é somente agente/produtor de mundo, mas também é produzido por ele, a partir das experiências que se apresentam. Ou seja, as experiências sensoriais de mundo são validadas, não desviantes, enfim, "normais" (não patológicas). Tal concepção é oposta ao pensamento biomédico, que "patologiza" a experiência de audição de vozes e sons, em vez de entendê-la como potencialidade do humano.

A diferença entre o sentido dado pela cultura popular e pela psiquiatria tradicional foi retratada através da análise de "um grande místico indiano" 57 nascido em Bengala e "uma louca internada em Paris no serviço do professor Janet"57, no século XIX. Ramakrishna foi venerado como santo e visto como sábio, enquanto Madeleine, que afirmava dormir com Deus, passou parte da vida internada em Salpêtrière.

0 indiano viveu em um país que ainda não havia tido influência da medicina ocidental, e Madeleine em uma França que já tinha uma ciência estruturada para o tratamento da loucura. Os dois personagens apresentavam ideias delirantes que podiam ser entendidas como místicas. No caso de Madeleine, foram 


\section{JOURNAIOF \\ NURSING \\ MOHEALTH}

ISSN 2236 - 1987

prática religiosa diária: “Eu vou continuar fazendo isso porque ela me fez o que eu sou". ${ }^{58}$

A cultura exerce, portanto, um papel determinante, tanto na patoplastia dos sintomas quanto na interpretação e sentido da experiência, e deve ser valorizada em sua análise. ${ }^{1}$ Os cenários apresentados nos permitem questionar 0 reducionismo biomédico e apontam a necessidade de ampliar o campo de compreensão sobre a alucinação auditiva como fenômeno especificamente humano, marcado pela biografia do sujeito e o contexto cultural do qual faz parte. A discussão sobre esse tema deve ser pautada não apenas pela sua explicação etiológica, mas pelos desdobramentos do cuidado na clínica e a criação de possibilidades de existência e convivência do próprio sujeito com sua experiência.

\section{CONCLUSÕES}

Desde a Antiguidade, o fenômeno da audição de vozes vem recebendo diferentes sentidos. Como vimos, a partir da Idade Moderna, sobrepõe-se a compreensão etiológica baseada em aspectos biológicos, e, ainda nos dias de hoje, não há consenso no meio científico quanto às causas e aos fatores envolvidos, apesar de inúmeras pesquisas traçarem correlações com acontecimentos de vida, o ambiente social e familiar, e com a cultura elemento este pelo qual a existência é estruturada. Essa questão reforça a necessidade de problematizarmos lógicas que enxerguem o fenômeno apenas de um ponto de vista, sem buscar explorar dimensões que fazem a dedicar-se a ajudar pessoas a encontrarem entes que haviam desaparecido, e continuou em sua 


\section{IOURNAIOF

sentido para os próprios ouvidores de vozes.

A era Moderna foi o período que marcou a virada sobre o significado não patológico de experiências alucinatórias, com inúmeras pesquisas e teorizações que contribuíram para a objetificação do fenômeno, esquecendo-se do principal elemento de análise: o ouvidor de vozes. Com isso fundaram as bases de uma psicopatologia medicalizadora e que contribui para a estigmatização social daqueles que escutam vozes - e sua consequente exclusão.

Poucos foram os atores que não envolveram tais características em suas práxis, com destaque para a psicanálise e movimentos de reforma psiquiátrica ocorridos na Europa a partir da segunda metade do século $X X$ - que não foram citados neste trabalho por terem envolvido o campo da saúde mental como um todo -, e, mais recentemente, pelo HVM/INTERVOICE. Esses movimentos resgataram a importância do protagonismo do ouvidor de vozes na compreensão do fenômeno.

Outro ponto a ser destacado é o sentido das vozes. Considerando que dar sentido às vozes é condição fundamental para entender o que está se passando com a pessoa que alucina, se esse sentido for o de patologia (como por exemplo no caso dos ouvidores de vozes dos EUA, citado no subtópico referente à cultura), talvez continuemos a presenciar o aumento da demanda por serviços de saúde e das queixas de pacientes quanto à eficácia das medicações. Isso sem contar a manutenção do ciclo de internações, a dependência ao tratamento, o sofrimento e estigma social (só para citarmos alguns fatores), que ouvidores enfrentam por quase toda a vida.

Reconhece-se que há casos em que a alucinação está associada a componentes orgânicos, ou a outros fatores, e que os medicamentos devem ser utilizados no tratamento. Ou que, mesmo não se tratando disso, o ouvidor de vozes queira fazer uso dos fármacos. Em qualquer conjuntura, quem deve decidir sobre o uso das medicações é o ouvidor de vozes e cada caso deve ser analisado, desde que se tenha em vista o que for melhor para o suporte - procedimento esse orientado e praticado pelo HVM/INTERVOICE.

Contextualizar os fenômenos por meio da história e da cultura é uma potente estratégia para abrir o campo de compreensão sobre eles e enxergar novas possibilidades de lida. Tal estratégia amplia, ainda, a capacidade de criação e os sentidos das relações, auxiliando as pessoas nos seus caminhos de liberdade - tarefas fundamentais para o trabalho clínico. Conclui-se que, ao se compreender as vozes como uma possibilidade de experiência humana e como linguagem, como fizeram os povos da Antiguidade e as culturas apresentadas, ficam evidentes outras possibilidades de saber-fazer com 0 fenômeno, através das quais cria-se uma condição essencial para a cura palavra latina que significa cuidado.

\section{REFERÊNCIAS}

1 Bauer SM, Schanda H, Karakula H, Olajossy-Hilkesberger L, Rudaleviciene $\mathrm{P}$, Okribelashvili $\mathrm{N}$, et al. Culture and 


\section{JOURNALOF \\ NURSING \\ ANO HEALTH}

ISSN 2236 - 1987

the prevalence of hallucinations in schizophrenia. psychiatry [Internet]. Comprehensive maio/june[cited $2018 \quad$ Aug 05];52(3):319-25. Available from: https://www.sciencedirect.com/scien ce/article/pii/S0010440X10000787?via \%3Dihub

2 Organização Mundial da Saúde. Classificação de transtornos mentais e de comportamento da CID-10. Porto Alegre: Artmed; 1993.

3 American Psychiatric Association. Manual diagnóstico e estatístico de transtornos mentais: DSM-5. Porto Alegre: Artmed; 2014.

4 Laroi F. How do auditory verbal hallucinations in patients differ from those in non-patients? Front hum neurosci [Internet]. 2012 Feb[cited 2018 Aug 05];6:1-9. Available from: https://www.ncbi.nlm.nih.gov/pmc/a rticles/PMC3282922/

5 Johns L, Kompus K, Connell M, Humpston C, Lincoln T, Longden $E$, et al. Auditory verbal hallucinations in persons with and without a need for care. Schizophr bull [Internet]. 2014 July[cited 2018 Aug 05];40(4 Suppl):S255-64. Available from: https://www.ncbi.nlm.nih.gov/pmc/a rticles/PMC4141313/

6 Thomas N, Hayward M, Peters E, Van Der Gaag M, Bentall RP, Jenner J, et al. Psychological therapies for auditory hallucinations (voices): current status and key directions for future research. Schizophr bull [Internet]. 2014 July[cited 2018 Aug 05];40(4 Suppl):S202-12. Available from: https://www.ncbi.nlm.nih.gov/pmc/a rticles/PMC4141318/

7 Ford JM, Morris SE, Hoffman RE, Sommer I, Waters F, McCarthy-Jones S, et al. Studying hallucinations within the NIMH RDoC framework. Schizophr bull [Internet]. 2014 July[cited 2018 Aug 05];40(4 Suppl):S295-04. Available from:

https: / /www.ncbi.nlm.nih.gov/pmc/a rticles/PMC4141312/

8 Paim I. História da psicopatologia. São Paulo: Editora Pedagógica e Universitária; 1993.

9 Echegaray E. Diccionario general etimologico de la lengua española. Madrid: José Maria Faquineto [Internet]. 1887 [acceso em 2016 Feb 09]. Disponible: https: / / archive.org

10 Lewis CT, Short C. A new latin dictionary. New York: Harper \& Brothers Publishers [Internet]. 1891 [cited 2016 Feb 09]. Available from: https://archive.org

11 Fleming MP, Martin CR. Genes and schizophrenia: A pseudoscientific Disenfranchisement of the individual. J psychiatr ment health nurs [Internet]. 2011 Aug[cited 2018 Aug 05];18(6):46978. Available from: https: / / onlinelibrary.wiley.com/doi/a bs/10.1111/j.1365-2850.2011.01690.x

12 Lambert MT, Laurel AC, Sampson N, Duffy SA. New-onset type-2 diabetes associated with atypical antipsychotic medications. Prog neuropsychopharmacol biol psychiatry [Internet]. 2006 July[cited 2018 Aug 05];30(5):919-23. Available from: https: / /www.sciencedirect.com/scien 


\section{NURSING \\ AND HEALTH}

ce/article/pii/S0278584606000650?via \%3Dihub

13 Kapur P, Hayes D, Waddingham R, Hillman S, Deighton J, Midgley N. The experience of engaging with mental health services among young people who hear voices and their families: a mixed methods exploratory study. BMC health serv res [Internet]. 2014 Nov[cited 2018 Aug 05];14:527-35. Available from: https://www.ncbi.nlm.nih.gov/pmc/a rticles/PMC4256811/

14 Nuevo R, Chatterji S, Verdes E, Naidoo N, Arango C, Ayuso-Mateos JL. The continuum of psychotic symptoms in the general population: a crossnational study. Schizophr bull [Internet]. 2012 May[cited 2019 Aug 05];38(3):475-85. Available from: https://www.ncbi.nlm.nih.gov/pmc/a rticles/PMC3329982/

15 Souza MT, Silva MD, Carvalho R. Revisão integrativa: o que é e como fazer. Einstein. 2010 [acesso em 2018 ago 05];8(1):102-6. Disponível em: http: / / www.scielo.br/pdf/eins/v8n1/ pt_1679-4508-eins-8-1-0102.pdf

16 Jaynes J. The origin of consciousness in the breakdown of the bicameral mind. New York: Houghton Mifflin Company; 2000.

17 Smith DB. Muses, madmen, and prophets: hearing voices and the borders of sanity. New York: Penguin Books; 2008.

18 Baker $P$. The voice inside: $a$ practical guide for and about people who hear voices. Port of Ness: P\&P Press; 2009.
ISSN 2236 - 1987

19 Platão. Fédon. $3^{a}$ ed. Belém: Editora UFPA; 2011.

20 Aristóteles. Parva Naturalia. $1^{a}$ ed. São Paulo: EDIPRO; 2012.

21 Castro TL. Das alucinações e ilusões [tese]. Rio de Janeiro (RJ): Faculdade de Medicina do Rio de Janeiro; 1889.

22 Ong WJ. The presence of the word: some prolegomena for cultural and religious history. New York: Simon \& Schuster; 2000.

23 Bíblia. A bíblia sagrada: antigo e novo testamento. $2^{a}$ ed. São Paulo: Sociedade Bíblica do Brasil; 1993.

24 Sarbin TR, Juhasz JB. The historical background of the concept of hallucination. J hist behav sci [Internet]. 1967 Oct[cited 2018 Aug 05];3(4):339-58. Available from: https://onlinelibrary.wiley.com/doi/a bs/10.1002/1520-

6696\%28196710\%293\%3A4\%3C339\%3A\%

3AAID-

JHBS2300030404\%3E3.0.CO\%3B2-U

25 Vernant JP. As origens do pensamento grego. Rio de Janeiro: Difel; 2002.

26 Le Goff J. Para uma outra Idade Média: tempo, trabalho e cultura no Ocidente. Petrópolis: Vozes; 2013.

27 Tomás de Aquino. Suma de teología. Madrid: Biblioteca de autores cristianos [Internet]. 2001 [acesso em 2016 ago 11]. Disponível em: http://biblioteca.campusdominicano. org/ 


\section{ISSN $2236-1987$}

28 Pessoti I. A loucura e as épocas. São Paulo: Editora 34; 1994.

29 Mackay CS. The hammer of witches: a complete translation of the Malleus Maleficarum. New York: Cambridge University Press; 2009.

30 Esquinsani RSS, Dametto J. Questões de gênero e a experiência da loucura na Antiguidade e na Idade Média. Estud sociol [Internet]. 2012 [acesso em 2018 ago 05];17(32):205$22 . \quad$ Disponível em: https://periodicos.fclar.unesp.br/est udos/article/view/4935/4124

31 Michelet J. Joana d'Arc. São Paulo: Hedra; 2007.

32 Ávila T. The interior castle or the mansions. London: Thomas Baker; 1921 (Obra original publicada em 1577) [Internet]. [cited 2016 June 20]. Available from: http://www.ccel.org/ccel/teresa/cas tle2

33 Freitag B. Habermas e a teoria da Modernidade. Cad CRH. 1995 jan/jun;22:138-63.

34 Calloni H. Ambientes desencantados: o século XVIII e o reino das racionalidades. Ambiente \& educação [Internet]. 2006 [cited 2018 Aug 05];11:11-27. Available from: https: //periodicos.furg.br/ambeduc/ article/viewFile/761/258

35 Berrios GE. Disorders of perception. In: Berrios GE. The history of mental symptoms: descriptive psychopathology since the nineteenth century. Cambridge: Cambridge University Press; 1996:35-69.
36 Foucault M. História da loucura. São Paulo: Perspectiva; 1991.

37 Esquirol E. Mental maladies: a treatise on insanity. (Obra original publicada em 1838). New York: Hafner; 1965.

38 Telles-Correia D, Moreira AL, Gonçalves JS. Hallucinations and related concepts - their conceptual background. Front psychol [Intenet]. 2015 July[cited 2018 Aug 05];6:1-9. Available from: https://www.ncbi.nlm.nih.gov/pmc/a rticles/PMC4515540/

39 Louzã Neto MR, Elkis H. Psiquiatria básica. $2^{\mathrm{a}}$ ed. Porto Alegre: Artmed; 2007.

40 Bleuler E. Dementia praecox or the group of schizophrenias. New York: Int Univ Press; 1969.

41 Elkis H. A evolução do conceito de esquizofrenia neste século. Rev bras psiquiatr [Internet]. 2000 maio[acesso em 2018 ago 05];1 Suppl:23-6. Disponível em: http://www.scielo.br/pdf/rbp/v22s1/ a09v22s1.pdf

42 Schneider K. Psicopatologia clínica. $2^{\mathrm{a}}$ ed. São Paulo: Mestre Jou; 1976.

43 Warner R, Girolamo G. Schizophrenia. Geneva: World Health Organization [Internet]. 1995 [cited 2016 Nov 19]. Available from: http: / /apps.who.int/

44 Romme $M$, Escher AD. Hearing voices. Schizophr bull. 1989;15(2):20916. 


\section{JOURNALOF \\ NURSING \\ ANO HEALTH}

ISSN 2236 - 1987

45 Escher S, Romme $M$. The hearing voices movement. In: Blom JD, Sommer IEC. Hallucinations: research and practice. New York: Springer; 2011:385-94.

46 Longden E, Corstens D, Dillon J. Recovery, discovery and revolution: the work of Intervoice and the hearing voices movement. In: Coles S, Keenan S, Diamond B. Madness contested: power and practice. Ross-on-Wye: PCCS Books; 2013:162.

47 Corstens D, Longden E, McCarthyJones S, Waddingham R, Thomas $\mathrm{N}$. Emerging perspectives from the hearing voices movement: implications for research and practice. Schizophr bull [Internet]. 2014 July[cited 2018 Aug 05];40(4 Suppl):S285-94. Available from:

https://www.ncbi.nlm.nih.gov/pmc/a rticles/PMC4141309/

48 Escher S. Making sense of voices: the relationship between the voices and the life history. In: Romme $M$, Escher S, Dillon J, Corstens D, Morris M. Living with voices: 50 stories of recovery. Birmingham City University: PCCS Books; 2009:54-62.

49 Romme $M$. What causes hearing voices? In: Romme M, Escher S, Dillon $J$, Corstens D, Morris M. Living with voices: 50 stories of recovery. Birmingham City University: PCCS Books; 2009:39-47.

50 Dillon J, Hornstein GA. Hearing voices peer support groups: a powerful alternative for people in distress. Psychosis [Internet]. 2013 Oct[cited 2018 Aug 05];5(3):286-95. Available from: https: / www.tandfonline.com/doi/ab s/10.1080/17522439.2013.843020?jour nalCode $=$ rpsy20

51 Laroi F, Luhrmann TM, Bell V, Christian WA, Deshpande $S$, Fernyhough $\mathrm{C}$, et al. Culture and hallucinations: overview and future directions. Schizophr bull [Internet]. 2014 July[cited 2018 Aug 05];40(4 Suppl):S213-20. Available from: https: / / academic.oup.com/schizophr eniabulletin/article/40/Suppl_4/S213 /1874317

52 Suhail K, Cochrane R. Effect of culture and environment on the phenomenology of delusions and hallucinations. Int j soc psychiatry [Internet]. 2002 June[cited 2018 Aug 05];48(2):126-38. Available from: http: //journals.sagepub.com/doi/abs /10.1177/002076402128783181?url_ve $\mathrm{r}=\mathrm{Z39} .88$ -

2003\&rfr_id=ori:rid:crossref.org\&rfr_d at=cr_pub\%3dpubmed

53 Luhrmann TM, Padmavati R, Tharoor $\mathrm{H}$, Osei A. Differences in voice-hearing experiences of people with psychosis in the USA, India and Ghana: interviewbased study. $\mathrm{Br} \mathrm{j}$ psychiatry [Internet]. 2015 Jan[cited 2018 Aug 05];206(1):414. Available from: https://www.cambridge.org/core/jou rnals/the-british-journal-ofpsychiatry/article/differences-invoicehearing-experiences-of-peoplewith-psychosis-in-the-usa-india-andghana-interviewbased-

study/A5DA3DC9FE1BD05439D676F182 2DD4DD

54 Menezes Bastos RJM. Audição do Mundo Apuàp II - Conversando com "animais", "espíritos" e outros seres. 


\section{NURSING \\ AND}

Ouvindo o aparentemente inaudível. Antropologia em primeira mão [Internet]. 2012 [acesso em 2018 ago 05];134:5-21. Disponível em: http: / /apm.ufsc.br/files/2012/11/13 4_rmbastos_audicao.pdf

55 Lagrou EM. O que nos diz a arte Kaxinawa sobre a relação entre identidade e alteridade? Mana. 2002 abr;8(1):29-61.

56 Santos-Granero F. Vitalidades sensuais: modos não corpóreos de sentir e conhecer na amazônia indígena. Rev antropol [Internet]. 2006 jan/jun[acesso em 2018 ago 05];49(1):93-131. Disponível em: http://www.scielo.br/pdf/ra/v49n1/v 49n1a04.pdf

57 Clément C, Kakar S. A louca e o santo. Rio de Janeiro: Relume-Dumará; 1997.

58 Martínez-Hernáez A. What 's behind the symptom?: on psychiatric observation and anthropological understanding. Amsterdan: Harwood Academic Publishers; 2000.

Data de publicação: 19/09/2018 